Research Article

\title{
Study of Post-Peak Strain Softening Mechanical Behaviour of Rock Material Based on Hoek-Brown Criterion
}

\author{
Qibin Lin $\mathbb{D}^{1},{ }^{1}$ Ping Cao, ${ }^{1}$ and Peixin Wang ${ }^{1,2}$ \\ ${ }^{1}$ School of Resources and Safety Engineering, Central South University, Changsha 410083, China \\ ${ }^{2}$ CCECC Fuzhou Survey and Design Institute Co. Ltd., Fuzhou 350013, China \\ Correspondence should be addressed to Qibin Lin; qblin@csu.edu.cn
}

Received 20 November 2017; Accepted 12 February 2018; Published 3 April 2018

Academic Editor: Claudio Tamagnini

Copyright (c) 2018 Qibin Lin et al. This is an open access article distributed under the Creative Commons Attribution License, which permits unrestricted use, distribution, and reproduction in any medium, provided the original work is properly cited.

In order to build the post-peak strain softening model of rock, the evolution laws of rock parameters $(m, s)$ were obtained by using the evolutionary mode of piecewise linear function regarding the maximum principle stress. Based on the nonlinear Hoek-Brown criterion, the analytical relationship of the rock strength parameters $(m, s)$, cohesion $(c)$, and friction angle $(\varphi)$ has been developed by theoretical derivation. According to the analysis on the four different types of rock, it is found that, within the range from 0 to $\sigma_{3 \mathrm{~min}}$, the peak hardness of the rock becomes smaller as the confining pressure increases and the degree of rock fragmentation decreases as well. The post-peak stress-strain curves obtained from the developed softening model are in good agreement with the laboratory test results under different confining pressures. In conclusion, the analytical method is reasonable, and it can predict the post-peak mechanical behaviour of rock well, which provides a new thought for the rocksoftening simulation.

\section{Introduction}

It is well known that the rock material is one type of heterogeneous brittle material with complex mechanical properties, which is significantly different from the metal material. In terms of post-peak strain softening characteristics, it is impossible to describe by the classical strength theory [1]. Many researchers have studied from different aspects regarding the post-peak strain softening behaviour. Rummel and Fairhurst [2] were one of the earliest researchers to study the general capabilities of post-peak compression tests of the rock. Tutluoglu et al. [3] gathered a lot of data related to the postfailure part of the stressstrain curve to study the relationship between prefailure and postfailure mechanical properties of the rock material. But the confining pressure on the post-peak mechanical behaviour of rock was not considered. Furthermore, the laboratory tests [4-8] show that the confining pressure greatly affected the post-peak mechanical behaviour of rock. Meng et al. [9] proposed a new evaluation method based on the magnitude and velocity of the post-peak stress drop, which accurately accounts for the influence of the confining pressure on strain softening. Alejano and Alonso [10] proposed a conveniently simple formulation of the dilatancy angle, which is capable of representing the rock sample's strain softening behaviour in compressive tests. Walton et al. [11] performed a series of uniaxial and triaxial tests and studied post-peak behaviour about the strength, deformability, and dilatancy at low confinement. Fang and Harrison [12] utilized the concept of a degradation index to describe the variation in degradation that rock exhibits when it is subjected to various confining pressures. Zhao et al. [13] established evolution laws of the strength parameters of soft mudstone at the post-peak stage by considering stiffness degradation. By introducing the concept of generalized friction angle and generalized cohesion, Lu et al. [14] constructed the post-peak computing model combined with FLAC code. Leontiev and Huacasi [15] and Filho and Leontiev [16] have conducted research from different angles on the post-peak mechanics of rock.

In order to study the post-peak strain softening mechanical properties of rock, the mechanical models described above are based on the Mohr-Coulomb criterion. However, the extent of rock damage was not studied in 


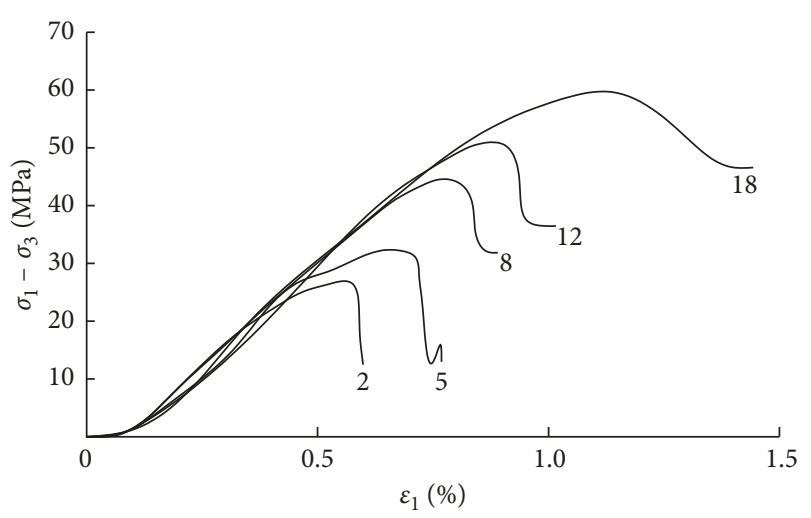

FIGURE 1: Complete stress-strain curves of Hawkesbury sandstone specimens under different confining stresses [18].

their studies. It is seldom to establish the post-peak strain softening model based on the Hoek-Brown criterion. Tan et al. [17] considered degradation and expansion behaviour of the rock constructing the post-peak strain softening model based on the Hoek-Brown criterion. The rock parameters $(m, s)$ in the Hoek-Brown criterion reflect the failure condition of rock reasonably. In this paper, piecewise linear function was used to obtain the evolution of rock strength parameters $(m, s)$. Accordingly, the analytical relationships among rock strength parameters $(m, s)$, friction angle $(\varphi)$, and cohesion $(c)$ were developed, and a new post-peak strain softening model was proposed. The verification with laboratory test results shows that the analytical model is reasonable to predict the post-peak rock behaviour.

\section{Simplification of Strain Softening Process}

Figure 1 shows a series of stress-strain curves of Hawkesbury sandstone specimens under different confining pressures [18]. It can be observed that the rock failure is a staged development process. With the increase of confining pressure, the rock post-peak strain softening behaviour is gradually transformed into ideal elastic-plastic behaviour. In order to process the main deformation and failure characteristics more informative in mathematics $[19,20]$, Figure 1 has been simplified to Figure 2. In Figure 2, the dash line indicates the stress-strain curve obtained by the experiment and the solid line represents the ideal stress-strain curve. The strain softening model is typically divided into three stages: pre-peak elastic deformation stage, post-peak strain softening stage, and residual stage.

\section{Analysis of the Rock Parameters of the Hoek-Brown Criterion and the Post-Peak Constitutive Model}

In the post-peak deformation stage, the development of strain softening is induced by the change of the rock strength parameters [12-14].

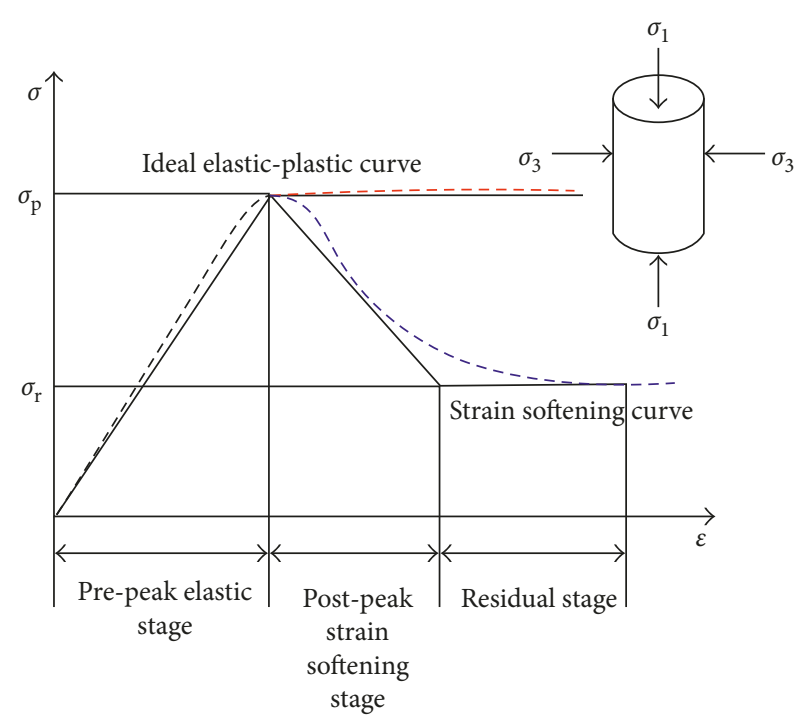

FIGURE 2: Test curves and idealized stress-strain curves.

3.1. Strength Criterion. According to the Hoek-Brown criterion [21],

$$
\sigma_{1}=\sigma_{3}+\sqrt{m(\eta) \sigma_{3} \sigma_{\mathrm{ci}}+s(\eta) \sigma_{\mathrm{ci}}^{2}}
$$

where $\sigma_{1}$ is the effective major principal stress, $\sigma_{3}$ is the effective minor principal stress, $\eta$ is the strain softening parameter, and $\sigma_{\mathrm{ci}}$ is the uniaxial compressive strength of intact rock. $m$ and $s$ are rock strength parameters; $s$ represents the degree of fragmentation of rock ranging from 0.0 to 1.0. For unfractured rock mass (i.e., rock), $s=1.0 . m$ represents the hardness of rock ranging from 0.0000001 to 25. For intact hard rock, $m=2.5$.

3.2. Strain Softening Parameters. There are usually two methods for selecting strain softening parameters. The first one is based on the increment method:

$$
\dot{\gamma}=\sqrt{\frac{2}{3}\left(\dot{\varepsilon}_{1}^{p} \dot{\varepsilon}_{1}^{p}+\dot{\varepsilon}_{2}^{p} \dot{\varepsilon}_{2}^{p}+\dot{\varepsilon}_{3}^{p} \dot{\varepsilon}_{3}^{p}\right)}
$$

wherein $\dot{\varepsilon}_{i}^{p}(i=1,2,3)$ represents the changing rate of the $i$ th principal plastic strain.

In another method, the strain softening parameter is considered as a function of the internal variable. The major principal strain $\varepsilon_{1}$, the major principal plastic strain $\varepsilon_{1 p}$, the plastic shear strain $\gamma_{1}$, and the equivalent plastic shear strain $\gamma_{2}$ are frequently used in this method:

$$
\begin{aligned}
& \gamma_{1}=\varepsilon_{1 \mathrm{p}}-\varepsilon_{3 \mathrm{p}}, \\
& \gamma_{2}=\sqrt{\frac{2}{3}\left(\varepsilon_{1}^{p} \varepsilon_{1}^{p}+\varepsilon_{2}^{p} \varepsilon_{2}^{p}+\varepsilon_{3}^{p} \varepsilon_{3}^{p}\right) .}
\end{aligned}
$$

As the rock parameters $(m, s)$ vary with the increase of the major principal strain, the major principal strain $\varepsilon_{1}$ from the above method is used as the softening parameter in this paper, which leads to ease of analytical calculation. 


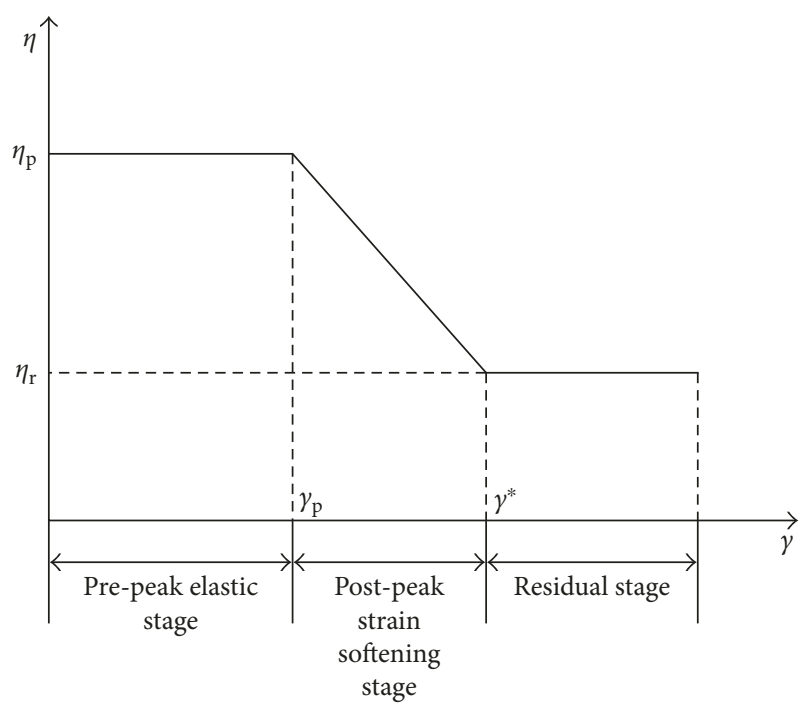

FIgURE 3: Variation of the strength parameter $\eta$ in the whole stressstrain curve.

3.3. Analysis of Rock Strength Parameters $(m, s)$ and the PostPeak Constitutive Model. The relationship between postpeak strength parameters and strain softening parameter, namely, the evolution of strength parameters, can be obtained by the laboratory experiment and numerical simulation. For simplicity, the mentioned relationship is often assumed as the form of a piecewise linear function [22-25], which can be expressed as

$$
\eta(\gamma)= \begin{cases}\eta_{\mathrm{p}}-\left(\eta_{\mathrm{p}}-\eta_{\mathrm{r}}\right) \frac{\gamma}{\gamma^{*}}, & \gamma_{\mathrm{p}}<\gamma<\gamma^{*} \\ \eta_{\mathrm{r}}, & \gamma \geq \gamma^{*},\end{cases}
$$

where $\eta, \eta_{\mathrm{p}}$, and $\eta_{\mathrm{r}}$ represent the strength parameter, strength parameter at the peak, and strength parameter at the starting point of the residual stage, respectively; $\gamma_{\mathrm{p}}$ and $\gamma^{*}$ are the critical softening parameter at the peak and strength parameter at the starting point of the residual stage, as shown in Figure 3.

According to (4), the evolution of rock strength parameters $(m, s)$ can be obtained:

$$
\begin{aligned}
& m(\varepsilon)=\left\{\begin{array}{lc}
m_{\mathrm{p}}-\left(\varepsilon_{1}-\varepsilon_{\mathrm{r}}\right) \frac{m_{\mathrm{p}}-m_{\mathrm{r}}}{\varepsilon_{\mathrm{r}}-\varepsilon_{\mathrm{p}}}, & \varepsilon_{\mathrm{p}}<\varepsilon<\varepsilon_{\mathrm{r}} \\
m_{\mathrm{r}}, & \varepsilon \geq \varepsilon_{\mathrm{r}},
\end{array}\right. \\
& s(\varepsilon)= \begin{cases}s_{\mathrm{p}}-\left(\varepsilon_{1}-\varepsilon_{\mathrm{r}}\right) \frac{s_{\mathrm{p}}-s_{\mathrm{r}}}{\varepsilon_{\mathrm{r}}-\varepsilon_{\mathrm{p}},} & \varepsilon_{\mathrm{p}}<\varepsilon<\varepsilon_{\mathrm{r}} \\
s_{\mathrm{r}}, & \varepsilon \geq \varepsilon_{\mathrm{r}},\end{cases}
\end{aligned}
$$

where $m_{\mathrm{p}}$ and $s_{\mathrm{p}}$ are the peak values of $m$ and $s ; m_{\mathrm{r}}$ and $s_{\mathrm{r}}$ are the peak residual values of $m$ and $s$; and $\varepsilon_{\mathrm{p}}$ and $\varepsilon_{\mathrm{r}}$ are the major principal strain values at the peak and at the starting point of the residual stage, respectively.

By substituting (5) and (6) into (1), the integration in (1) may be carried out analytically, and the post-peak strain softening constitutive model can be obtained accordingly.

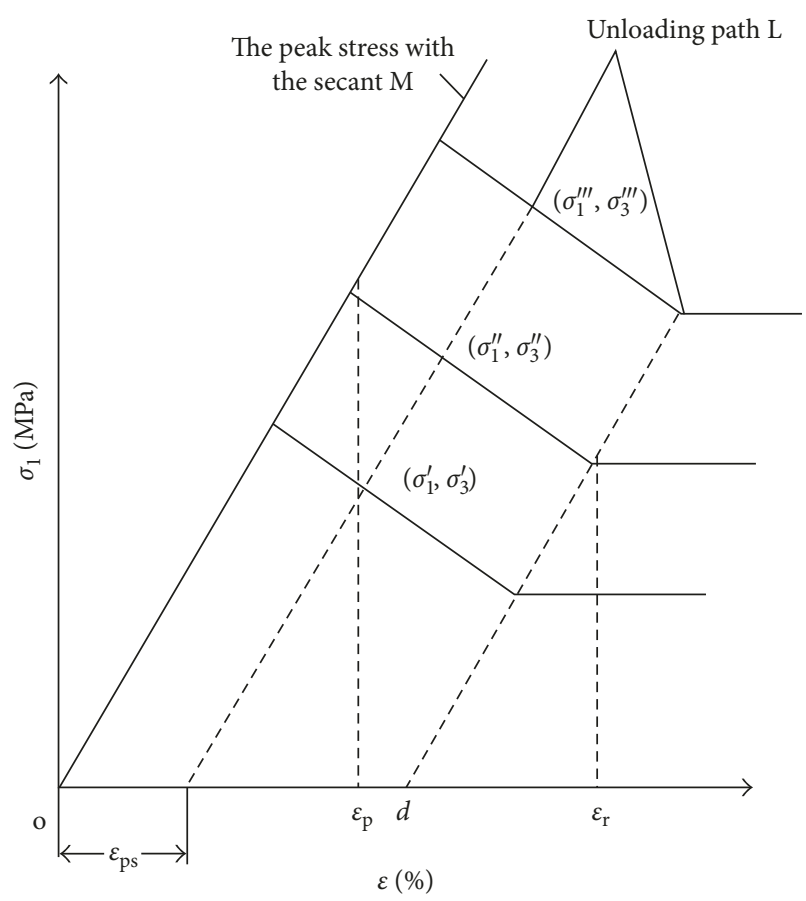

Figure 4: Post-peak strain softening simplified model stress states under the same unloading path.

\section{Analytical Study of Hoek-Brown Parameters}

Before calculation by (5) and (6), the strength parameters $(m, s)$ at the peak and the starting point of the residual stage should be determined. In rock engineering, strength parameters $(m, s)$ are generally determined by Geological Strength Index (GSI). However, it is difficult to use such a method to indicate strength parameters for rock specimens. Therefore, the paper proposes to use the Mohr-Coulomb strength criterion to obtain strength parameters $(c, \varphi)$ at the peak and at the starting point of the residual stage under different confining pressures. The strength parameters $(m, s)$ can be obtained via the relationship between themselves and the strength parameters $(c, \varphi)$ afterwards.

4.1. Strength Parameters $(c, \varphi)$ at the Peak and the Starting Point of the Residual Stage. Cohesion $c$ and friction angle $\varphi$ at the peak and the starting point of the residual stage under different confining pressures are various [26]. The paper assumes that any point in the post-peak stage is satisfied with the Mohr-Coulomb ultimate failure condition during the elastic unloading process. In this case, the unloading path $\mathrm{L}$ is parallel with the secant $M$ at the peak, as shown in Figure 4. The same plastic shear strain $\left(\varepsilon_{\mathrm{ps}}\right)$, under different confining pressures and the same unloading path, corresponds to a series of different ultimate stress states: $\left(\sigma_{1}^{\prime}, \sigma_{3}^{\prime}\right),\left(\sigma_{1}^{\prime \prime}, \sigma_{3}^{\prime \prime}\right)$, and $\left(\sigma_{1}^{\prime \prime \prime}, \sigma_{3}^{\prime \prime \prime}\right)$. By using the above method, the groups of different ultimate stress at the peak and the starting point of the residual stage can be obtained and displayed as Mohr stress circles in Figure 5. According to several Mohr stress circles, the envelope can be drawn. Thus, the corresponding cohesion $c$ and friction angle $\varphi$ at the peak and the starting point of the residual stage under different confining pressures can be obtained by analysis of the Mohr strength straight lines through the tangent points of envelopes. 


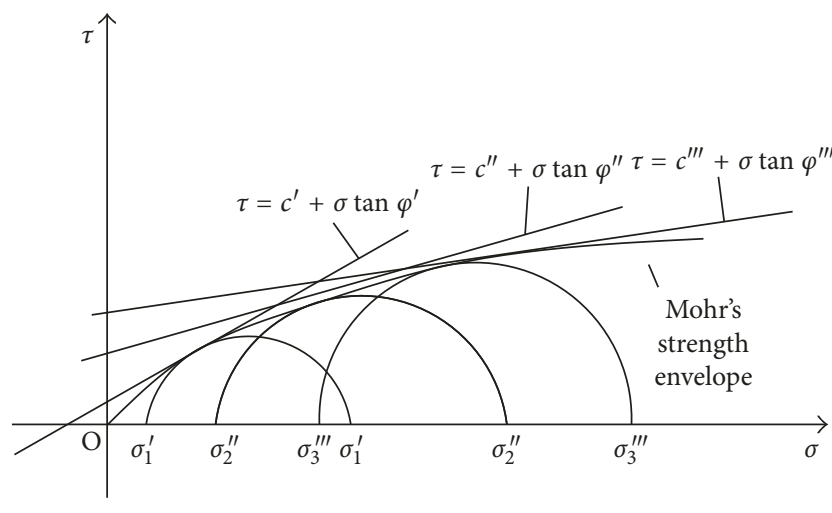

FIGURE 5: Mohr diagram for the tested specimens at the same plastic shear strain $\varepsilon_{\mathrm{ps}}$ under different confining pressures [9].

4.2. Analytical Derivation. Uniaxial compressive strength of rock mass may be expressed as [27]

$$
\sigma_{\mathrm{cm}}=\sqrt{s} \sigma_{\mathrm{ci}} .
$$

Uniaxial tensile strength of rock mass may be written as [12]

$$
\sigma_{\mathrm{tm}}=\frac{1}{2} \sigma_{\mathrm{ci}}\left(m-\sqrt{m^{2}+4 s}\right) .
$$

By combining with the Mohr-Coulomb criterion, cohesion $c$ and friction angle $\varphi$ can be obtained [28]:

$$
\begin{aligned}
& c=\frac{1}{2} \sqrt{-\sigma_{\mathrm{cm}} \cdot \sigma_{\mathrm{tm}}}, \\
& \varphi=\tan ^{-1}\left(\frac{\sigma_{\mathrm{cm}}+\sigma_{\mathrm{tm}}}{2 \sqrt{-\sigma_{\mathrm{cm}} \cdot \sigma_{\mathrm{tm}}}}\right) .
\end{aligned}
$$

By combining (7)-(10), the relationship among $m, s, \sigma_{\mathrm{ci}}$, $c$, and $\varphi$ can be obtained:

$$
\begin{aligned}
c^{2} & =\frac{1}{8} \sqrt{s} \sigma_{\mathrm{ci}}^{2}\left(\sqrt{m^{2}+4 s}-m\right), \\
\tan ^{2} \varphi & =\frac{\left[2 \sqrt{s}+\left(m-\sqrt{m^{2}+4 s}\right)\right]^{2}}{8 \sqrt{s}\left(\sqrt{m^{2}+4 s}-m\right)} .
\end{aligned}
$$

Equations (11) and (12) can be modified to the following equations:

$$
\begin{aligned}
c^{2} & =\frac{1}{8} A B \sigma_{\mathrm{ci}}^{2}, \\
\tan ^{2} \varphi & =\frac{[2 B-A]^{2}}{8 A B},
\end{aligned}
$$

where

$$
\begin{aligned}
& A=\sqrt{m^{2}+4 s}-m, \\
& B=\sqrt{s} .
\end{aligned}
$$

By combining (13)-(16), the following results can be expressed:

$$
\begin{aligned}
& A=\frac{4 c}{\sigma_{\mathrm{ci}}}\left(\sqrt{\tan ^{2} \varphi+1}-\tan \varphi\right), \\
& B=\frac{2 c}{\sigma_{\mathrm{ci}}}\left(\sqrt{\tan ^{2} \varphi+1}+\tan \varphi\right) .
\end{aligned}
$$

Substituting (17) and (18) into (15) and (16), the following equations are obtained:

$$
\begin{aligned}
& s=\frac{4 c^{2}}{\sigma_{\mathrm{ci}}^{2}}\left(\sqrt{\tan ^{2} \varphi+1}+\tan \varphi\right)^{2}, \\
& m=\frac{8 c}{\sigma_{\mathrm{ci}}} \tan \varphi \cdot \sqrt{\tan ^{2} \varphi+1} \cdot\left(\sqrt{\tan ^{2} \varphi+1}+\tan \varphi\right) .
\end{aligned}
$$

After substituting the strength parameters $(c, \varphi)$ at the peak and the starting point of the residual stage into (19) and (20), the rock strength parameters $(s, m)$ at the peak and the starting point of the residual stage can be calculated accordingly.

Equations (19) and (20) show that the rock strength parameters $(s, m)$ are related to the uniaxial compressive strength of intact rock $\sigma_{\mathrm{ci}}$, friction angle $\varphi$, and cohesion $c$, which can be expressed as

$$
\begin{aligned}
s & =f\left(\sigma_{\mathrm{ci}}, c, \varphi\right), \\
m & =f\left(\sigma_{\mathrm{ci}}, c, \phi\right) .
\end{aligned}
$$

In terms of several groups of $\left(\sigma_{1}, \sigma_{3}\right)$ under different confining pressures, $\sigma_{\mathrm{ci}}$ is calculated [10]:

$$
\sigma_{\mathrm{ci}}=\sqrt{\frac{\sum y}{n}-\left\{\frac{\sum x y-\left(\sum x \sum y / n\right)}{\sum x^{2}-\left[\left(\sum x\right)^{2} / n\right]}\right\} \frac{\sum x}{n}}
$$

where $x=\sigma_{3}, y=\left(\sigma_{1}-\sigma_{3}\right)^{2}$, and $n$ is the number of groups of data.

\section{Verification and Discussion}

5.1. Application of the Developed Analytical Method. In order to verify the developed post-peak strain softening model, the triaxial compression test results of the Hawkesbury sandstone [18] were used. The strength parameters $(c, \varphi)$ at the peak and the starting point of the residual stage for the Hawkesbury sandstone were calculated via the above analytical method, and the results are shown in Table 1 . According to (22), $\sigma_{\text {ci }}$ of the Hawkesbury sandstone is $21.21 \mathrm{MPa}$.

Substituting the data in Table 1 into (19) and (20), the corresponding rock strength parameters $(m, s)$ at the peak and the starting point of the residual stage are obtained and listed in Table 2.

It can be observed from Table 2 that the rock strength parameter $s$ is greater than 1.0, which is contradicted with the defined range of $s$ (from 0 to 1.0). The reason is that the cohesion $c$ and the friction angle $\varphi$ are obtained based on the Mohr-Coulomb strength criterion. There is a maximum limit of confining pressure $\left(\sigma_{3 \max }\right)$ for linear fitting between the Mohr-Coulomb criterion and Hoek-Brown criterion [29], as shown in Figure 6. 
TABle 1: Data of the Hawkesbury sandstone in triaxial compression tests.

\begin{tabular}{|c|c|c|c|c|c|c|}
\hline \multirow{2}{*}{ Confining pressure $(\mathrm{MPa})$} & \multicolumn{3}{|c|}{ At the peak } & \multicolumn{3}{|c|}{ At the starting point of the residual stage } \\
\hline & $\varepsilon_{\mathrm{p}}\left(10^{-3}\right)$ & $c_{\mathrm{p}}(\mathrm{Mpa})$ & $\varphi_{\mathrm{p}}\left({ }^{\circ}\right)$ & $\varepsilon_{\mathrm{r}}\left(10^{-3)}\right.$ & $c_{\mathrm{r}}(\mathrm{Mpa})$ & $\varphi_{\mathrm{r}}\left({ }^{\circ}\right)$ \\
\hline 2 & 5.5 & 5.66 & 31.9 & 6.3 & 0.79 & 32.7 \\
\hline 5 & 6.5 & 6.46 & 27.4 & 8.0 & 1.74 & 28.7 \\
\hline 8 & 7.7 & 10.28 & 19.2 & 9.0 & 4.89 & 21.5 \\
\hline 12 & 8.8 & 12.19 & 14.2 & 10.0 & 7.05 & 15.3 \\
\hline 18 & 12.3 & 14.17 & 9.6 & 13 & 8.61 & 9.9 \\
\hline
\end{tabular}

TABLE 2: Rock strength parameters $(m, s)$ at the peak position and at the starting residual stage.

\begin{tabular}{|c|c|c|c|c|c|c|c|}
\hline \multirow[t]{2}{*}{ Confining pressure (MPa) } & \multicolumn{3}{|c|}{ At the peak } & \multicolumn{3}{|c|}{$\begin{array}{l}\text { At the starting point of the } \\
\text { residual stage }\end{array}$} & \multirow{2}{*}{$S_{\mathrm{p}} / S_{\mathrm{r}}$} \\
\hline & $\varepsilon_{\mathrm{p}}\left(10^{-3}\right)$ & $m_{\mathrm{p}}$ & $s_{\mathrm{p}}$ & $\varepsilon_{\mathrm{r}}\left(10^{-3}\right)$ & $m_{\mathrm{r}}$ & $s_{\mathrm{r}}$ & \\
\hline 2 & 5.5 & 1.99 & 0.46 & 6.3 & 0.29 & 0.01 & 48.00 \\
\hline 5 & 6.5 & 1.65 & 0.50 & 8.0 & 0.49 & 0.04 & 13.09 \\
\hline 8 & 7.7 & 1.42 & 0.93 & 9.0 & 0.98 & 0.33 & 4.06 \\
\hline 12 & 8.8 & 1.09 & 0.99 & 10.0 & 0.70 & 0.38 & 2.87 \\
\hline 18 & 12.3 & 0.77 & 1.25 & 13.0 & 0.48 & 0.47 & - \\
\hline
\end{tabular}

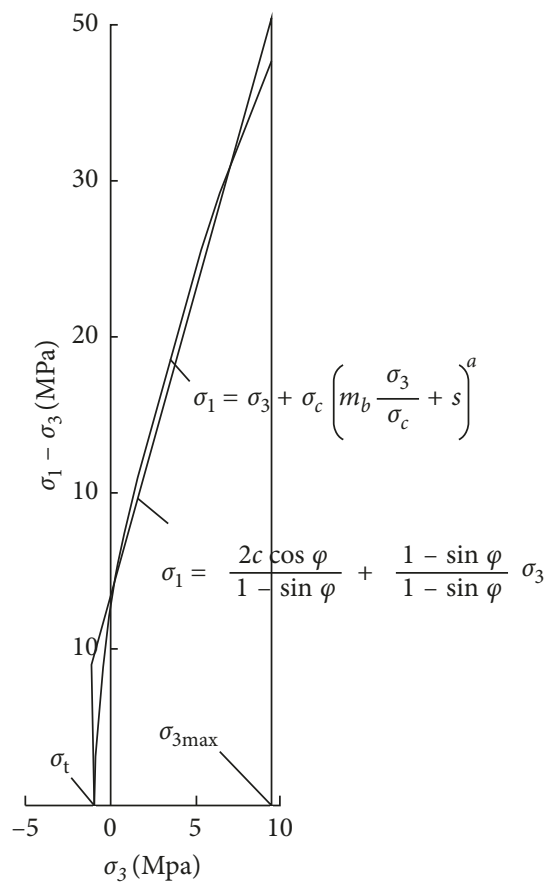

FIGURE 6: Relationships between the minimum and maximum principal stresses for equivalent Hoek-Brown and Mohr-Coulomb criteria [29].

In terms of the upper limit of the maximum confining pressure $\left(\sigma_{3 \max }\right)$ obtained in rock engineering, it is mainly influenced by the engineering experience and classification. It is suggested in this paper that the value of the maximum confining pressure $\left(\sigma_{3 \max }\right)$ can be reached when the strength parameter $(s)$ value is equal to 1.0. In this elastic state, the rock specimen is in peak strength under the confining pressure. Furthermore, the internal structure of the specimen is unfractured; therefore, Hoek-Brown and MohrCoulomb criteria could be used to fit its stress-strain curve.

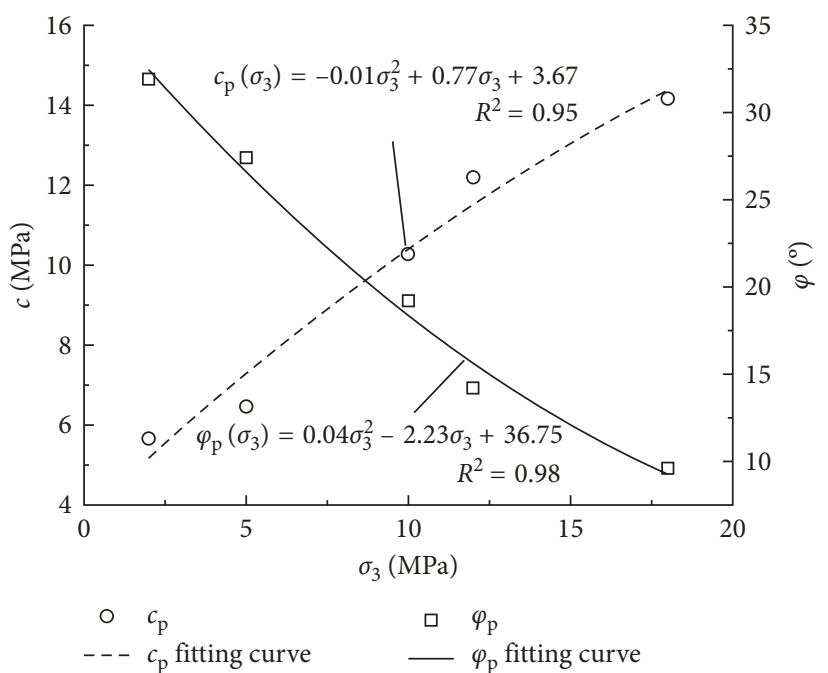

FIGURE 7: Relationship of $c$ or $\varphi$ changing with confining pressure at the peak.

On the contrary, once this upper limit of the maximum confining pressure is exceeded, it is unmeaningful to use the Hoek-Brown criterion or Mohr-Coulomb criterion since the calculated results display deviation from the real ones. In other words, it is no necessary to define a value to $s$.

As indicated in Tables 1 and 2, the cohesion and friction angle at the peak and the starting point of the residual stage change with the confining pressure. It may be concluded that cohesion $(c)$ and friction angle $(\varphi)$ are a function of the confining pressure $\sigma_{3}$. By conducting secondary fitting of $c$, $\phi$, and $\sigma_{3}$ in Table 1, the fitting result is shown in Figures 7 and 8 , and the fitting functions are

$$
\begin{array}{ll}
c_{\mathrm{p}}\left(\sigma_{3}\right)=-0.01 \sigma_{3}^{2}+0.77 \sigma_{3}+3.67, & R^{2}=0.95, \\
\varphi_{\mathrm{p}}\left(\sigma_{3}\right)=0.04 \sigma_{3}^{2}-2.23 \sigma_{3}+36.75, & R^{2}=0.98,
\end{array}
$$




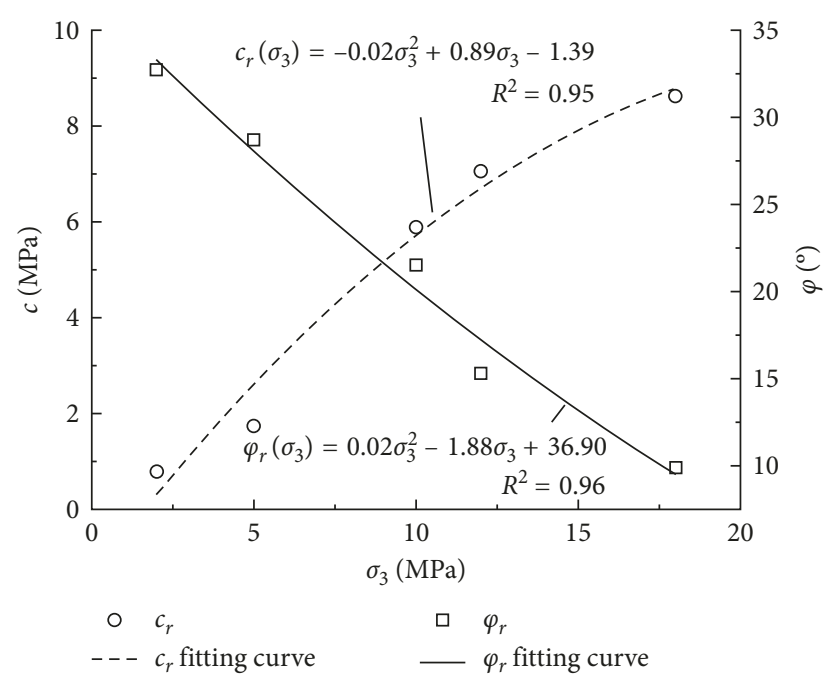

FIGURE 8: Relationship of $c$ or $\varphi$ changing with confining pressure at the starting point of the residual stage.

$$
\begin{array}{cc}
c_{\mathrm{r}}\left(\sigma_{3}\right)=-0.02 \sigma_{3}^{2}+0.89 \sigma_{3}-1.39, & R^{2}=0.95, \\
\varphi_{\mathrm{r}}\left(\sigma_{3}\right)=-0.02 \sigma_{3}^{2}-1.88 \sigma_{3}+36.90, & R^{2}=0.96 .
\end{array}
$$

Substituting (23) and (24) into (19), the maximum confining pressure $\sigma_{3 \max }$ is calculated to be $12.1 \mathrm{MPa}$ when $s=1$ in (19).

It can be found from Table 2 that when the specimen reaches the peak strength, $m_{\mathrm{p}}(2 \mathrm{MPa})>m_{\mathrm{p}}(5 \mathrm{MPa})>$ $m_{\mathrm{p}}(8 \mathrm{MPa})>m_{\mathrm{p}}(12 \mathrm{MPa})$ and $s_{\mathrm{p}}(2 \mathrm{MPa})<s_{\mathrm{p}}(5 \mathrm{MPa})<$ $s_{\mathrm{p}}(8 \mathrm{MPa})<s_{\mathrm{p}}(12 \mathrm{MPa})$.

Within a certain range of confining pressure and increasing confining pressure at the peak, $m_{\mathrm{p}}$ becomes smaller while $s_{\mathrm{p}}$ becomes greater. It can be concluded that the increase of confining pressure results in smaller hardness at the peak and better rock quality. With the increase of confining pressure, rock develops gradually from brittle to ductile, which results in increased plasticity, reduced brittleness, and reduced hardness. It is interesting to note that as a result of the increase of confining pressure, the internal extent of the damage becomes smaller and the fragmentation influences less when the rock reaches the peak.

By substituting the corresponding values of $m$ and $p$ for the confining pressures of $2,5,8$, and $12 \mathrm{MPa}$ into (5) and (6), the analytical results of such two equations can be obtained and substituted into (1). Thus, the post-peak strain softening model of the Hawkesbury sandstone can be established. Figure 9 displays the comparison between the whole stress-strain curves of numerical simulation and triaxial compression tests for the Hawkesbury sandstone.

5.2. Discussion of Results. In order to verify the analytical results, the same analytical method was carried out with laboratory results of the representative rock types: Indiana limestone [26], Tennessee marble [7], and Hegang granite [7]. Table 3 presents the axial strains and the rock parameters

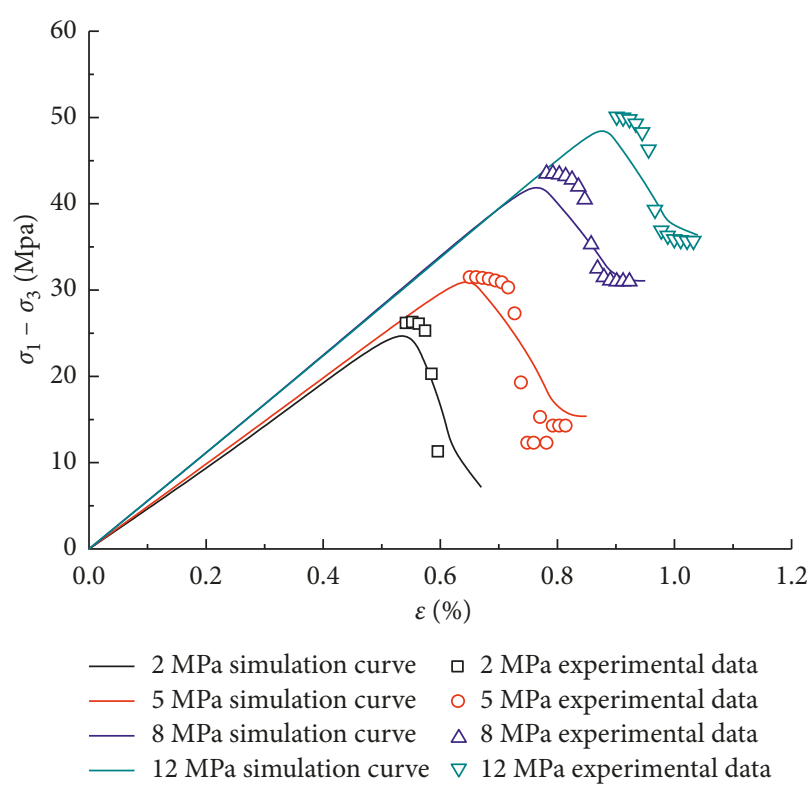

Figure 9: Comparison between Hawkesbury sandstone triaxial compression test data and numerical simulation curves.

$(m, s)$ of different rock types corresponding to the peak strength and residual strength. The values of $S_{\mathrm{p}} / S_{\mathrm{r}}$ are related to different confining pressures. Figures 9-11 illustrate the comparison chart between the numerical simulation and experimental data for the Hawkesbury sandstone, Tennessee marble, and Hegang granite, respectively.

As can be seen from Figures 9-12, numerical simulation is consistent with experimental data trends within a certain range of confining pressure, and the numerical simulation value agrees well with actual experimental values, especially for peak strength and residual strength. It indicates that the post-peak strain softening model established in the paper is reasonable, and it can accurately describe the mechanical post-peak behaviour of rock.

For better understanding of the post-peak softening characteristics and the degree of fragmentation and the degree of brittleness of rock, the brittleness index is proposed for $S_{\mathrm{p}} / S_{\mathrm{r}}$. Figure 13 illustrates the relationship among $S_{\mathrm{p}} / S_{\mathrm{r}}$, confining pressure, and rock type.

As the confining pressure decreases, $S_{\mathrm{p}} / S_{\mathrm{r}}$ gradually decreases and tends to become stable finally. In other words, as the confining pressure increases, the rock gradually develops brittleness to ductility. Influenced by the confining pressure, the performance of brittleness of different types of rock is varying. The results also show that the reaction of the Hawkesbury sandstone is the most violent, followed by the Hegang granite and Tennessee marble.

\section{Conclusion}

A reasonable post-peak strain softening model plays an important role in the analysis of rock behaviour. Based on the nonlinear Hoek-Brown criterion, a post-peak strain softening model was proposed in this paper, and the conclusions are listed below: 
TABLE 3: Rock strength parameters $(m, s)$ of different rock types at the peak position and at the starting point of the residual stage.

\begin{tabular}{lcccccccc}
\hline Rock type & Confining pressure $(\mathrm{MPa})$ & $\varepsilon_{\mathrm{p}}\left(10^{-3}\right)$ & $m_{\mathrm{p}}$ & $s_{\mathrm{p}}$ & $\varepsilon_{\mathrm{r}}\left(10^{-3}\right)$ & $m_{\mathrm{r}}$ & $s_{\mathrm{r}}$ & $S_{\mathrm{p}} / S_{\mathrm{r}}$ \\
\hline & 2 & 3.4 & 7.67 & 0.47 & 5.5 & 1.17 & 0.03 & 16.94 \\
Indiana limestone & 4 & 4.2 & 3.81 & 0.71 & 6.3 & 1.25 & 0.05 & 16.60 \\
& 8 & 5.0 & 2.86 & 0.86 & 8.1 & 2.15 & 0.19 & 4.79 \\
& 12 & 5.9 & 2.70 & 0.98 & 8.0 & 2.25 & 0.40 & 2.52 \\
Tennessee marble & 3 & 2.4 & 4.1 & 0.84 & 3.2 & 2.54 & 0.12 & 7.00 \\
& 7 & 2.8 & 4.0 & 0.85 & 3.8 & 2.50 & 0.15 & 5.67 \\
& 14 & 3.2 & 3.9 & 0.92 & 4.9 & 2.42 & 0.22 & 4.18 \\
Hegang granite & 21 & 3.5 & 3.2 & 1.00 & 6.0 & 1.80 & 0.31 \\
& 2 & 4.2 & 18.83 & 0.37 & 5.6 & 2.36 & 0.02 & 24.18 \\
& 5 & 5.5 & 14.44 & 0.44 & 8.8 & 2.45 & 0.02 & 19.82 \\
& 10 & 6.7 & 13.50 & 0.64 & 12.6 & 2.53 & 0.09 & 7.29 \\
& 15 & 7.5 & 11.99 & 0.98 & 20.0 & 2.95 & 0.15 & 6.63 \\
\hline
\end{tabular}

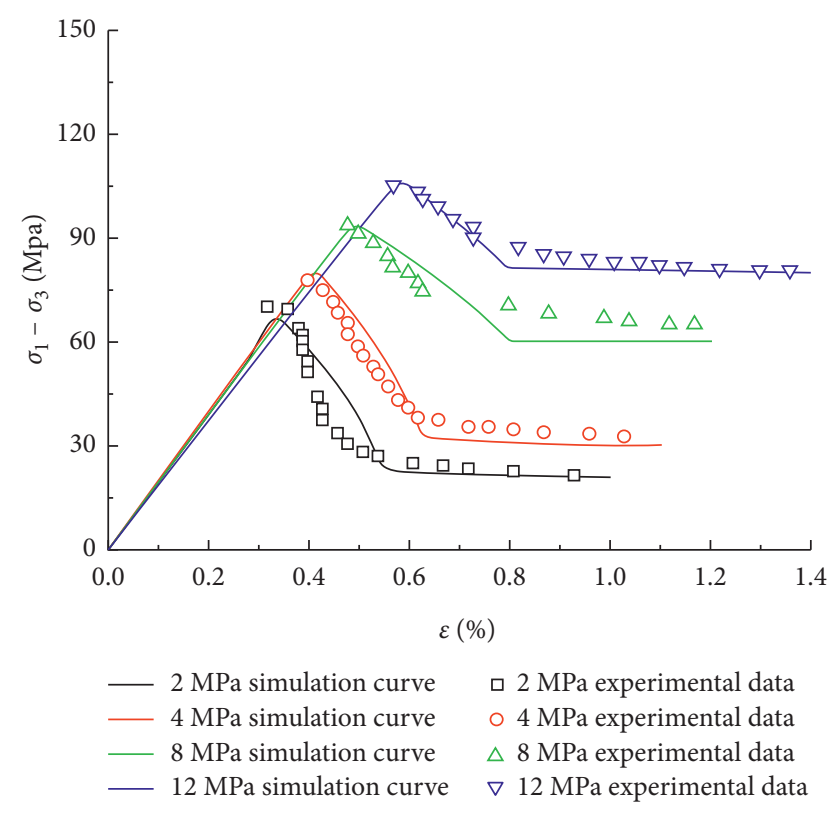

Figure 10: Comparison between Indiana limestone triaxial compression test data and numerical simulation curves.

(1) Based on the Hoek-Brown criterion, the maximum principal strain $\varepsilon_{1}$ was selected as the softening parameter. The piecewise linear function was used to evaluate the rock strength parameters $(m, s)$, and the post-peak strain softening model was obtained accordingly.

(2) By theoretical derivation, the analytical relation of parameters $(m, s)$, cohesion $(c)$, and friction angle $(\varphi)$ is determined. The cohesion $(c)$ and friction angle $(\varphi)$ under different confining pressures can be obtained regarding any points of the post-peak stage. This developed relationship helps to establish a nonlinear post-peak strain softening model.

(3) The laboratory test results of the Hawkesbury sandstone show that with the increase of confining pressure, the rock hardness in peak strength becomes smaller. However, the degree of rock fragmentation in peak strength becomes lower within the range of

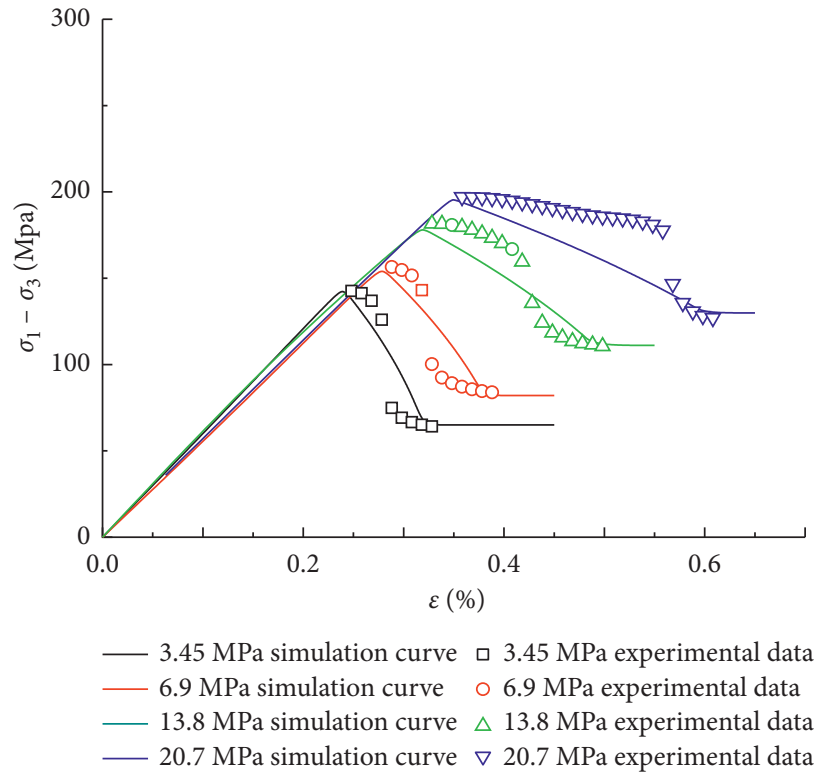

Figure 11: Comparison between Tennessee marble triaxial compression test data and numerical simulation curves.

confining pressure from 0 to $\sigma_{3 \min }$. When the rock strength parameter $(s)$ reaches 1 , the upper limit of the confining pressure $\sigma_{3 \max }$ for best fitting between the Hoek-Brown criterion and Mohr-Coulomb criterion can be obtained.

(4) The analytical results of the developed strain softening model have been verified with laboratory results of the Hawkesbury sandstone, Indiana limestone, Tennessee marble, and Hegang granite. The results of the analytical method and laboratory tests are in good agreement, and it is concluded that the proposed model can predict the post-peak mechanical properties of the rock accurately.

(5) Different types of rock may have different values of $S_{\mathrm{p}} / S_{\mathrm{r}}$. The value of $S_{\mathrm{p}} / S_{\mathrm{r}}$ is related to the influence of the confining pressure on the brittleness of rock. As the confining pressure increases, the value of $S_{\mathrm{p}} / S_{\mathrm{r}}$ obtained from the same rock type becomes small, which results in the weakened brittleness. 


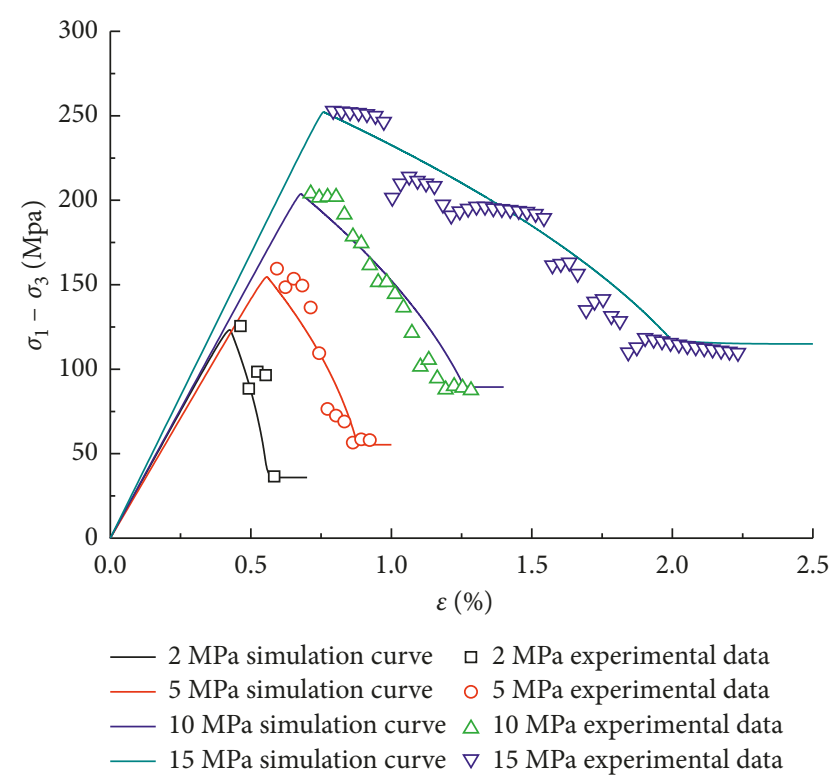

Figure 12: Comparison between Hegang granite triaxial compression test data and numerical simulation curves.

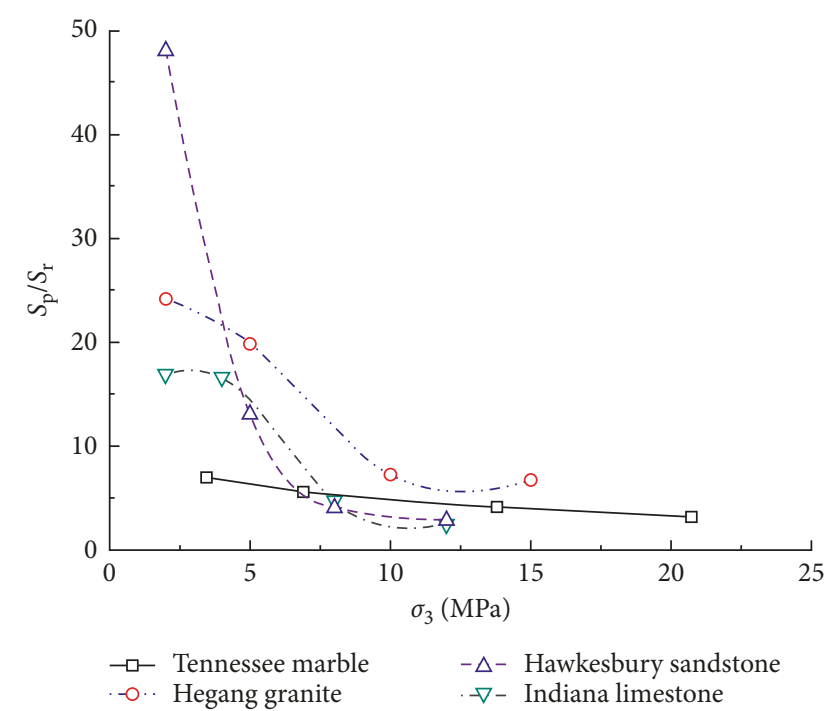

Figure 13: Relationships between $S_{\mathrm{p}} / S_{\mathrm{r}}$ and confining pressure for different types of the rock.

\section{Conflicts of Interest}

The authors declare that they have no conflicts of interest.

\section{Acknowledgments}

The authors would like to acknowledge the financial support from the National Natural Science Foundation of China (51174228 and 11772358).

\section{References}

[1] M. S. Diederichs, "Manuel rocha medal recipient rock fracture and collapse under low confinement conditions," Rock
Mechanics and Rock Engineering, vol. 36, no. 5, pp. 339-381, 2003.

[2] F. Rummel and C. Fairhurst, "Determination of the postfailure behavior of brittle rock using a servo-controlled testing machine," Rock Mechanics, vol. 2, no. 4, pp. 189-204, 1970.

[3] L. Tutluoglu, I. FeridOge, and C. Karpuz, "Relationship between pre-failure and post-failure mechanical properties of rock material of different origin," Rock Mechanics and Rock Engineering, vol. 48, no. 1, pp. 121-141, 2015.

[4] R. P. Tiwari and K. S. Rao, "Post failure behaviour of a rock mass under the influence of triaxial and true triaxial confinement," Engineering Geology, vol. 84, no. 3, pp. 112-129, 2006.

[5] L. Cui, J. J. Zheng, R. J. Zhang, and Y. K. Dong, "Elasto-plastic analysis of a circular opening in rock mass with confining stress-dependent strain-softening behaviour," Tunnelling and Underground Space Technology, vol. 50, no. 1, pp. 94-108, 2015.

[6] S. Wang, H. Zheng, C. Li, and X. Ge, "A finite element implementation of strain-softening rock mass," International Journal of Rock Mechanics and Mining Sciences, vol. 48, no. 1, pp. 67-76, 2011.

[7] H. Lin, W. Xiong, and Q. X. Yan, "Three-dimensional effect of tensile strength in the standard Brazilian test considering contact length," Geotechnical Testing Journal, vol. 39, no. 1, pp. 137-143, 2016.

[8] J. Liu, P. Cao, and D. Y. Han, "The influence of confining stress on optimum spacing of TBM cutters for cutting granite," International Journal of Rock Mechanics and Mining Sciences, vol. 88, pp. 165-174, 2016.

[9] F. Meng, H. Zhou, C. Zhang, R. Xu, and J. Lu, "Evaluation methodology of brittleness of rock based on post-peak stress-strain curves," Rock Mechanics and Rock Engineering, vol. 48, no. 5, pp. 1787-1805, 2015.

[10] L. R. Alejano and E. Alonso, "Considerations of the dilatancy angle in rocks and rock masses," International Journal of Rock Mechanics and Mining Sciences, vol. 42, no. 4, pp. 481-507, 2006.

[11] G. Walton, J. Arzúa, L. R. Alejano, and M. S. Diederichs, "A laboratory-testing-based study on the strength, deformability, and dilatancy of carbonate rocks at low confinement," Rock Mechanics and Rock Engineering, vol. 48, no. 3, pp. 941-958, 2015.

[12] Z. Fang and J. P. Harrison, "A mechanical degradation index for rock," International Journal of Rock Mechanics and Mining Sciences, vol. 38, no. 8, pp. 1193-1199, 2001.

[13] Z. H. Zhao, W. M. Wang, and X. Gao, "Evolution laws of strength parameters of soft rock at the post-peak considering stiffness degradation," Journal of Zhejiang Universityence A, vol. 15, no. 4, pp. 282-290, 2014.

[14] Y. L. Lu, L. G. Wang, F. Yang, Y. Li, and H. Chen, "Post-peak strain softening mechanical properties of weak rock," Chinese Journal of Rock Mechanics and Engineering, vol. 29, no. 3, pp. 640-648, 2010.

[15] A. Leontiev and W. Huacasi, "Mathematical programming approach for unconfined seepage flow problem," Engineering Analysis with Boundary Elements, vol. 25, no. 1, pp. 49-56, 2001.

[16] O. P. Filho and A. Leontiev, "An optimization approach for unconfined seepage problem with semipermeable conditions," Structural and Multidisciplinary Optimization, vol. 39, no. 6, pp. 581-588, 2009.

[17] X. Tan, H. Konietzky, and T. Frühwirt, "Numerical simulation of triaxial compression test for brittle rock sample using 
a modified constitutive law considering degradation and dilation behavior," Journal of Central South University, vol. 22, no. 8, pp. 3097-3107, 2015.

[18] P. L. P. Wasantha, W. J. Darlington, and P. G. Ranjith, "Characterization of mechanical behaviour of saturated sandstone using a newly developed triaxial apparatus," Experimental Mechanics, vol. 53, no. 5, pp. 871-882, 2013.

[19] M. Cai, P. K. Kaiser, H. Uno, Y. Tasaka, and M. Minami, "Estimation of rock mass deformation modulus and strength of jointed hard rock masses using the GSI system," International Journal of Rock Mechanics and Mining Sciences, vol. 41, no. 1, pp. 3-19, 2004.

[20] M. Cai, P. K. Kaiser, Y. Tasaka, and M. Minami, "Determination of residual strength parameters of jointed rock masses using the GSI system," International Journal of Rock Mechanics and Mining Sciences, vol. 44, no. 2, pp. 247-265, 2007.

[21] E. Hoek, "Strength of jointed rock masses," Géotechnique, vol. 33, no. 33, pp. 187-223, 1983.

[22] Y. K. Lee and S. Pietruszczak, "A new numerical procedure for elasto-plastic analysis of a circular opening excavated in a strain-softening rock mass," Tunnelling and Underground Space Technology Incorporating Trenchless Technology Research, vol. 23, no. 5, pp. 588-599, 2008.

[23] N. J. Higham, "The numerical stability of barycentric Lagrange interpolation," IMA Journal of Numerical Analysis, vol. 24, no. 4, pp. 547-556, 2004.

[24] H. Wang, H. Lin, and P. Cao, "Correlation of UCS rating with Schmidt hammer surface hardness for rock mass classification," Rock Mechanics and Rock Engineering, vol. 50, no. 1, pp. 195-203, 2017.

[25] L. R. Alejano, E. Alonso, A. Rodríguez-Dono, and G. Fernández-Manín, "Application of the convergenceconfinement method to tunnels in rock masses exhibiting Hoek-Brown strain-softening behaviour," International Journal of Rock Mechanics and Mining Sciences, vol. 47, no. 1, pp. 150-160, 2010.

[26] T. Gentzis, N. Deisman, and R. J. Chalaturnyk, "Geomechanical properties and permeability of coals from the foothills and mountain regions of western Canada," International Journal of Coal Geology, vol. 69, no. 3, pp. 153-164, 2007.

[27] E. Hoek and E. T. Brown, "Empirical strength criterion for rock masses," Journal of the Geotechnical Engineering Division, vol. 106, no. 15715, pp. 1013-1035, 1982.

[28] E. Hoek and E. T. Brown, "Practical estimates of rock mass strength," International Journal of Rock Mechanics and Mining Sciences, vol. 34, no. 8, pp. 1165-1186, 1997.

[29] E. Hoek, C. T. Carranza-Torres, B. Corkum, E. Hoek, and C. Carranza-Torres, "Hoek-Brown failure criterion-2002 Edition," in Proceedings of the NARMS-TAC Conference, Toronto, ON, Canada, July 2002.

[30] C. Sun, S. G. Zhang, B. X. Jia, and Z. Q. Wu, "Physical and numerical model tests on post-peak mechanical properties of granite," Yantu Gongcheng Xuebao/Chinese Journal of Geotechnical Engineering, vol. 37, no. 5, pp. 847-852, 2015. 


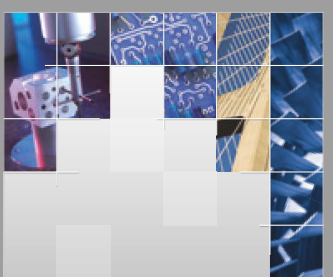

\section{Enfincering}
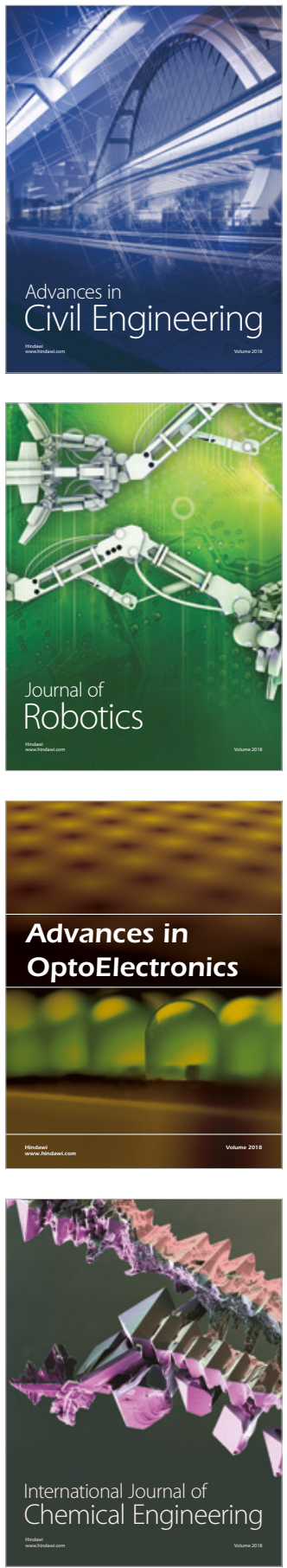

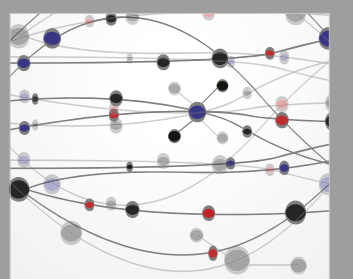

\section{Rotating \\ Machinery}

The Scientific World Journal

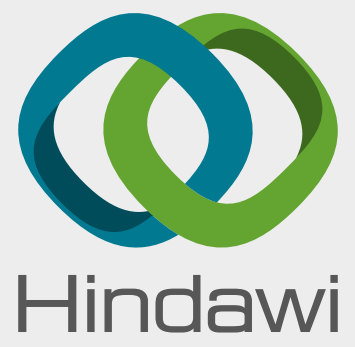

Submit your manuscripts at

www.hindawi.com
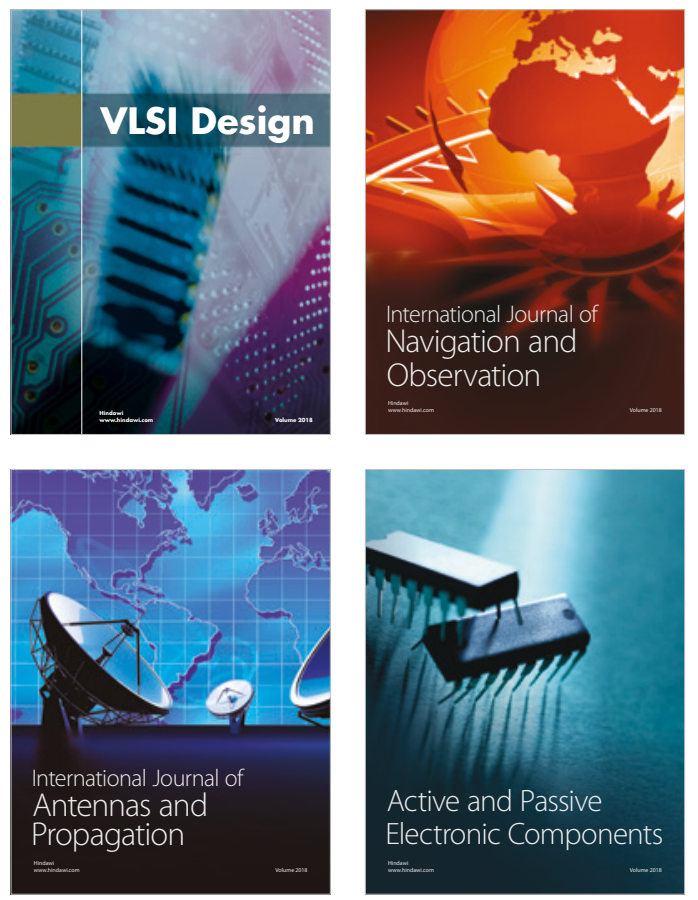
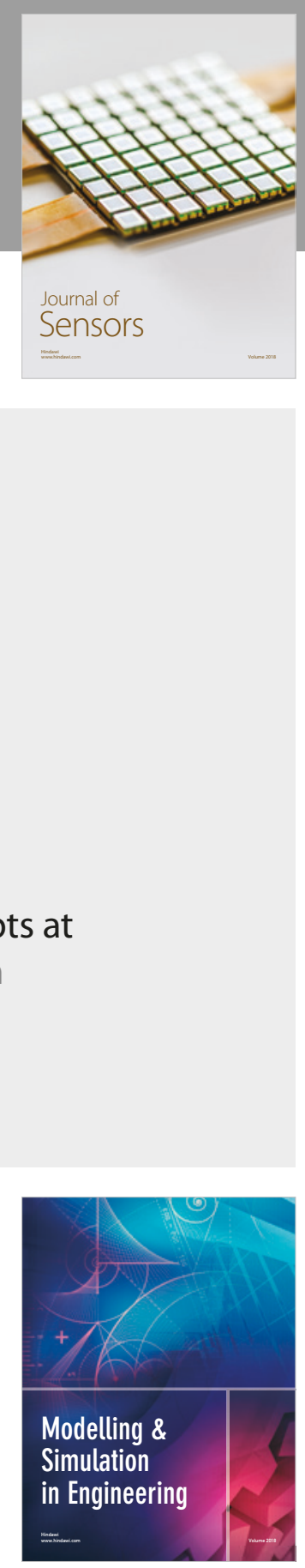

\section{Advances \\ Multimedia}
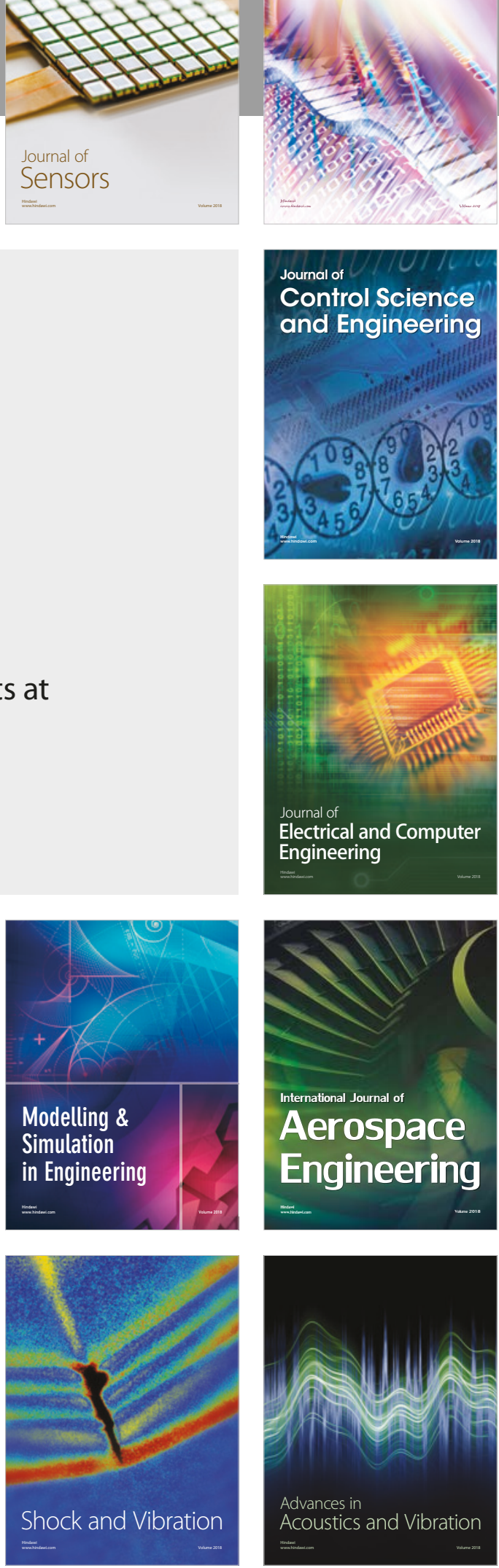